\title{
XXVI. A consideration of the effects of contraction during the cooling of intrusive masses of granite and the cause of their solid continuity
}

\section{T. Mellard Reade C.E. F.G.S. F.R.I.B.A.}

To cite this article: T. Mellard Reade C.E. F.G.S. F.R.I.B.A. (1889) XXVI. A consideration of the effects of contraction during the cooling of intrusive masses of granite and the cause of their solid continuity , Philosophical Magazine, 27:166, 233-237, DOI: 10.1080/14786448908628343

To link to this article: http://dx.doi.org/10.1080/14786448908628343

曲 Published online: 29 Apr 2009.

Submit your article to this journal $\llbracket$

山 Article views: 2

Q View related articles ¿ 
is, supplemented by the energy, or a portion of the energy, due to the hydration or solution of the solid salts, and may have values which accord with the heat of formation of the dissolved salts.

IV. That in those cases in which there is no chemical attraction, or a very feeble attraction between the water and the salt, the negative heat of solution is derived from sensible heat, and is not supplied by the free energy of the chemical change. All cells in which such salts are employed opposed to zinc should have negative "thermovoltaic constants", and evolve heat when they send a current forwards.

V. That when metals, whose salts have purely negative heats of solution, are opposed to metals whose salts they can replace, the E.M.F. set up is in excess of the total thermal change. Such cells, therefore, absorb sensible heat when worked forwards.

VI. That, taking the foregoing facts into consideration, no cell exists which can furnish an E.M.F. in excess of the free energy of the chemical change; $i . e$. which can convert sensible heat into electric energy working at uniform temperature. (Negatives the supposition concerning mercury and other cells.)

VII. That certain metals have a tendency to form films of sub-salts on their surfaces, the formation of which giving rise, as it does, to a different thermochemical reaction, naturally furnishes an E.M.F. which does not correspond with the values calculated from the heats of formation of their normal salts. (Ex.gr. copper in cupric chloride, mercury in mercuric chloride, probably silver in most soluble chlorides.)

VIII. That the electromotive force of a voltaic cell furnishes a more accurate measurement of the "free energy," and therefore of true chemical affinity, than data derived from calorimetric observations.

XXVI. A Consideration of the Effects of Contraction during the Cooling of Intrusive Masses of Granite and the Cause of their Solid Continuity. By T. Mellard Reade, C.E., F.G.S., F.R.I.B.A.*

$\mathrm{N}^{\mathrm{O}}$ doubt many geological observers have wondered, on looking at an intrusive granite-mass such as Cairnsmore of Fleet in Kirkcudbrightshire, or that of Shap Fells in

* Communicated by the Author. 
Westmoreland, to find so little evidence of contraction. If, ps we have every reason to believe, the granite has once been in a state of igneous fluidity, it would at first sight seem reasonable to expect more evidences of coniraction than what are usually manifest. The late David Forbes was so much struck with this in Norway that he instituted a set of experiments to test the statement of Bischof that granite contracts from 10 to 25 per cent. in volume in cooling. His results in the casting of highly siliceous slags showed only a contraction of from 0.014 to 0.028 . Forbes did not attach great weight to these experiments as accurate determinations in consequence of the difficulty of getting a perfectly solid casting, but considered that they pioved Bischof to have much overestimated the contraction of granite. Let us consider what the process of contraction is, and in what way granitemasses are likely to be affected by it.

In casting ironwork it is usual to allow in the pattern $\frac{1}{10}$ of an inch per linear foot for the contraction of the iron $=\frac{1}{12} 0$ of the whole length, or a contraction in volume of $\frac{1}{40} 0^{\text {. This }}$ is not, however, the contraction from a fluid state, for the exterior cools first, and, at the time of solidification, is as large as the pattern. The contraction of iron in passing from the fluid to the solid state or in "freezing" is therefore not determined by this practice, and I am not aware of any reliable determination of its amount; indeed some have contended that it expands in freezing, because cold iron will float in molten iron.

Be this as it may, I think we can get some hints of the operations of nature from the processes of the ironfounder. For instance, in casting a large sphere, say 2 feet in diameter, it is necessary, to prevent the honeycombing of the central part, to keep feeding the ball as the metal cools. It would seem that the outer skin takes the exact size and form of the mould on solidification, and the metal cools and congeals from the exterior to the centre. By keeping the centre fed with new molten metal a sound casting is insured. In the same way any one who has been in the habit of making castings in lead is aware of the sudden disappearance of the lead in the feeding-throat on congelation taking place, so that unless a good plug be left a deep hole will occur in the casting at the point where the metal has been poured in. Both these phenomena point towards sudden contraction on congelation.

Let us now consider the case of a granite-mass. It is extremely probable that in many cases these masses are more or less like what Mr. Gilbert has called Laccolites or stone 
cisterns*, and are, in fact, reservoirs fed from a throat below. In other cases it may be possible that they are connected with the central igneous magma of the earth in a larger way, as tongues or protrusions of it. When this is the case it is difficult to realize the enormous amount of heat-energy brought up from below to be expended on the overlying sediments in the way of mountain-building. Whether the granite intrusion be fed by a throat, or whether it be a tongue of molten matter, as it cools and congeals within the bowels of the earth (which it must do at an extremely slow rate) the uprising stream will introduce compensating matter in the same manner as does the plug in casting. The only difference will be that the one runs in by gravitation, the other is forced up by pressure from below. But while the matter is rising it is also eating into the surrounding sediments and incorporating them into its own body. And it is well here to remember that granite is of a higher specific gravity than most sedimentary rocks, in the proportion of about $2 \cdot 90$ to $2 \cdot 30$, or, in other words, a ton of granite contains from 11.8 to 12.8 cubic feet, while a ton of sandstone contains from $14 \cdot 3$ to $17 \cdot 3$ cubic feet. Therefore, if we for the sake of illustration assume a sandstone to consist of the same elements as a granite, it will, on incorporation with the molten mass, actually decrease in volume. Of course the amount of decrease would vary with the composition of the sandstone. Again, if the surrounding rock were marl it would decrease in a greater ratio.

There are thus two forces at work-one the absorption of the surrounding rock and its decrease in volume, the other the introduction of new matter, the total effect tending towards disruption by increasing bulk. This effect may be seen in any good granite contact. There is generally a laminated gneissic band between the granite and the enclosing rock, and often they are so welded together that junction specimens showing both structures can be taken and cut for the microscope. It is not improbable that the fragments of gneissic rock found in granite may be, so to speak, broken off from the walls of the intrusion.

Sigis of lateral displacement of the surrounding rock to a considerable extent are also sometimes seen. But what is it that prevents the disruption and fissuring of the granite by contraction after solidification takes place?

I answer gravitation, for one thing; for so long as the rock will yield as a paste, the rnass above, which in most cases is supposed to have been very considerable, will keep it com-

* Geology of the Henry Mountains. 
pressed and in contact with the surrounding walls. When the granite has by cooling solidified sufficiently to be unaffected in this way, other agencies come into play. I have shown * that variations of temperature of a small amount extending over a large area will produce an intermittent creep of the strata in one direction, so that the surrounding rock is continually being forced up against the granite.

That considerable variations of temperature are constantly taking place in regions of intrusion is tolerably certain, and that the heat of these intrusive masses is very slowly imparted to the encircling rocks is shown by the extremely slow cooling of some lava-streams that are only protected from the atmosphere by a thin covering; whereas granite is often in enormous masses and deeply buried. Some of these masses must have taken thousands of years to cool. In addition to the lateral creep already spoken of, there is another force tending to compression in the gravitation of the surrounding and partially uplifted rock which naturally tends to close up any shrinkage of the intrusive mass.

It follows from this that granite-masses do not show signs of shrinkage such as Forbes looked for, not because the material does not shrink but because, from one reason or another, it is kept throughout its history in a state of compression. When the contraction of the under-mass takes place on a large scale, then the granite may be sheared by normal faulting, as I have described in chap. viii. 'Origin of Mountain-Ranges,' like any other rock-mass.

Granite intrusion may take place without creating much disturbance, but when it occurs in large masses, such as in the core of Mont Blanc and in other Alpine regions, from the amount of new matter forced in from below, it must become a very potent factor in producing lateral pressure. The fan-structure which we see in such regions is in my opinion produced by the gradual spreading out of the probably semi-plastic matter by gravitation; indeed it seems impossible that it can be due to any other cause. This idea is not a new one by any means; the celebrated architect Viollet le Duc has shown that expansion and intrusion of the protogene in the core of Mont Blanc has caused the folding back of the beds which it has forced apart $\dagger$. The effects of gravitation as a geological agent has lately been

* Origin of Mountain-Ranges, p. 329.

$\dagger$ Mont Blanc, by Eugène Viollet le Duc ; translated by B. Bucknall, 1877, chap. i. 
treated of by Mr. W. Barlow in a paper read before the Geological Society, which, although the author may claim rather too much for his favourite force, shows in many ways how, by simple gravitation, elevated masses of the earth produce lateral pressure*.

We thus see that while expansion-forces below the surface of the earth produce both lateral compression, uplift, or lateral creep, the effect of gravitation is to intensify the lateral pressure and movement near the surface and to keep the materials closely in contact during and after contraction. Some of the critics of my theory of the origin of mountainranges have found a difficulty in understanding how, if the rise of the isogeotherms produces uplift by expansion, the fall of the isogeotherms does not produce an equivalent sinking by contraction and obliterate the range.

The question is really fully answered in the book itself, in which it is shown that the materials of a mountain-range are by the effects of expansion, or a series of expansions, moved towards and piled up into the range, and that they cannot be drawn back and spread out in the areas from which they have moved. Nothing, in fact, can remove them save denudation.

The effect of contraction is to produce normal faulting, and this occurs most largely in the areas from which the materials of the range have travelled. The mode of action is really in one aspect very fairly shown in the experiments on the expansion of metal plates, of which I have given many illustrations. The total decrease of bulk of the section of the earth's crust, out of which the mountain-range has been elaborated, may eventually equal the previous increase which has produced the range, but the form is entirely altered. Subsidence may bring the sea back to the foot of the mountains, or, carried further, may make islands of them ; but it cannot obliterate them any more than the subsidence of the ground on which a volcano stands can obliterate it.

A mountain-range grows upwards by compression, a volcano principally by accretion; but they both indicate, though in different ways, a redisposition of materials which it takes denuding agencies geological ages to efface.

* Q. J. G. S. November 1888, pp. 783-796. 